\title{
Environmental Data Observation System-Solam for Analysis and Interpretation of Soil Moisture Variation and Precipitation Indexes
}

\author{
Laura Vanessa Araque Lavalle, Rodrigo A. Stabile, Cassiano A. Bortolozo, Rodolfo M. Mendes, \\ João V. C. Garcia, Mariana F. B. Motta, Marcio R. M. Andrade, Téhrrie König, Daniel Metodiev \\ National Center for Monitoring and Early Warning of Natural Disasters (CEMADEN/MCTIC), São José dos Campos, Brazil \\ Email: lauraaraquelavalle@gmail.com,rodrigo.stabile@cemaden.gov.br cassianoab@gmail.com,rodolfo.mendes@cemaden.gov.br, \\ marianabenessiuti@yahoo.com.br, marcio.andrade@cemaden.gov.br, tehrriekonig@gmail.com, daniel.metodiev@cemaden.gov.br
}

How to cite this paper: Lavalle, L.V.A., Stabile, R.A., Bortolozo, C.A., Mendes, R.M., Garcia, J.V.C., Motta, M.F.B., Andrade, M.R.M., König, T. and Metodiev, D. (2018) Environmental Data Observation System-Solam for Analysis and Interpretation of Soil Moisture Variation and Precipitation Indexes. International Journal of Geosciences, 9, 658-667. https://doi.org/10.4236/ijg.2018.911039

Received: September 19, 2018

Accepted: November 23, 2018

Published: November 26, 2018

Copyright $\odot 2018$ by authors and Scientific Research Publishing Inc. This work is licensed under the Creative Commons Attribution International License (CC BY 4.0).

http://creativecommons.org/licenses/by/4.0/

\begin{abstract}
The monitoring of urban slopes employing in-situ equipment seeks to avoid the loss of human lives midst emergency events like landslides. Cemaden (Brazilian National Centre for Monitoring and Early Warnings of Natural Disasters) has a pilot network of soil moisture and rain gauge stations located in urban slopes to understand, prevent, and mitigate landslides. Due to the large volume of data produced by this system there was a need for tools for data retrieval and visualization. This paper describes the Solam (Environmental Data Observation System) software which generates automated graphs that enable researchers to analyze and comprise data from soil moisture sensors and rain gauge stations. Those results allow to research moisture variations in six different sensor levels (from $0.5 \mathrm{~m}$ to $3 \mathrm{~m}$ deep) and precipitation indexes (hourly and accumulated rainfall) for the established period. This analysis will provide information to set critical environmental thresholds on base recorded landslides.
\end{abstract}

\section{Keywords}

Slope Stability, Geotechnical Monitoring, Environmental Thresholds, Urban Slopes, Software, Warning System

\section{Introduction}

Cemaden is a Federal Brazilian Institution responsible for monitoring and issuing natural disaster early warnings that subsidize safeguarding lives, and reducing the social, environmental, and economic vulnerability resulting from 
these events. The Center was conceived from the need to understand and recognize those processes so that their effects can be obviated or mitigated by predicting of their occurrence.

The landslides monitored usually occur on urban slopes located in the most vulnerable areas, where the lower income population lives. The soil in this area was modified by the action anthropological and these landslides usually form from shallow surfaces that generally occur after significant and long duration rainfall [1].

At present alerts are issued based on weather forecast and data collected by rain gauge stations. To improve the early warning issuing a project was created to monitor soil moisture on slopes with high risk of landslides occurrence; therefore Cemaden has installed 5 Data Collection Platform (DCP), in a test area in Campos do Jordão, São Paulo State, Brazil.

It is important to monitor soil moisture because it represents one of the triggers of mass movement. The loss of stability of the aggregate soil can occur through the constant infiltration of water, which modifies the initial conditions of soil water pore pressure [2].

Each DCP has a pluviometer and various profiles with sensors for different depths that allow determining the soil moisture. This system measures the sensors, stores the measurements, and transmits the data to a receiving station. Figure 1 presents the installed equipment.

The first DCP was installed in 2014, and a large volume of instrumentation data has been generated. Therefore, it was developed the Solam software that enables the automated and automatic treatment to understand the registered field data.

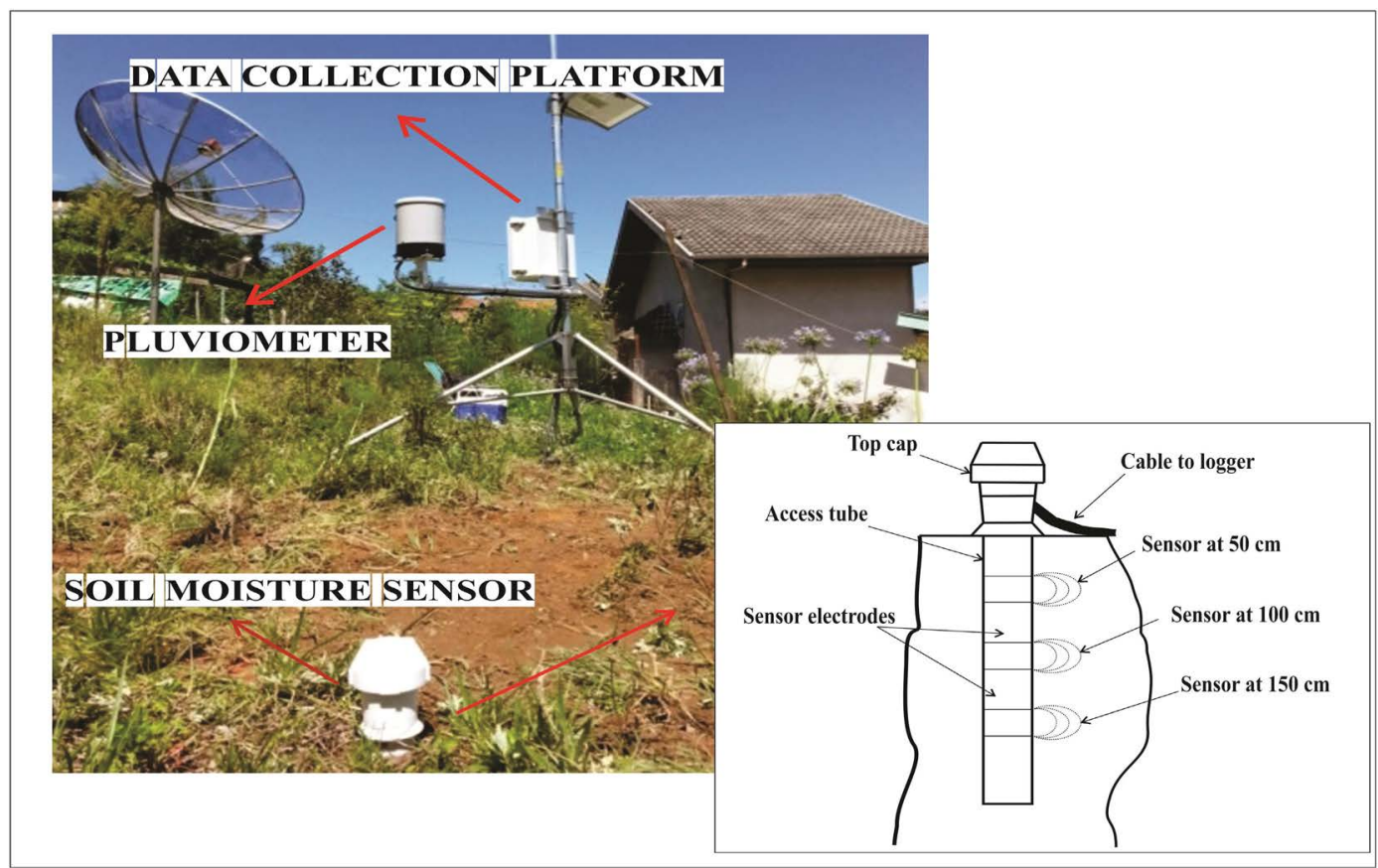

Figure 1. Data collection platform. Profile of the soil moisture sensor. 
This text aims to present the features of the developed software and how to define critical values, as well as monitoring the environment in real time.

\section{Study Area}

In the state of São Paulo, Campos do Jordão is a high elevation city (1.628 m) with several landslide risk areas. The Vila Albertina neighborhood is one risk area where DCP were installed to monitor rainfall levels and the variation in soil moisture. Figure 2 shows the location where the study was conducted. The DCP 4 was installed in Morro de Britador risk area (Figure 2), another neighborhood with a large historical record of landslide occurrences. The most emblematic landslide disaster there occurred in January of 2000 when 8 deaths and 1840 homeless were recorded [3].

Due to the tropical location of Campos do Jordão, the soil structure is characterized by a fragile balance and soil use ranging com extreme vulnerable to inadequate, justifying the typical geological problems of the region. This scenario, added to continuous unplanned urbanization, magnified the risk of landslides in urban slopes, causing social, economic and environmental damages [3] [4] [5].

The main variable influencing slope stability is the rainfall that reaches means of $1800 \mathrm{~mm} /$ year, of which about $800 \mathrm{~mm}$ occur between December and February [6].

The soil moisture is one of the variables most important to define the critical condition of stability in urban slopes because the increase of water in the pores of soil generate an environment where the mechanical strength between the particles decreases, meaning low suction to create a rupture surface in the soil mass

Therefore, the increase in water pore-pressure combined with characteristics of the soil (hydraulic, physical and mechanical) and some environmental factors (vegetation cover and climatic conditions) create scenarios with high probability of disaster [7].

Because of the continuous and disorderly urban expansion of the city, there was a growth in the landslides risk areas, where construction processes generated an increase or relief of loads (cuts and embankments). These changes in the natural conditions of the soil have produced more vulnerable slopes. Furthermore, haphazardly elimination of the original vegetation the elimination produces a modification in the natural regime of flow and infiltration of waters in the slopes [3] [5] [8].

In Campos do Jordão the water content in the soil varies a lot during the year [9], due to the heavy rain season over the summer (November - February) and the dry period (June - September). For this reason, the summer is the most critical time for the city.

According to the Campos do Jordão risk map developed by the National Geological Institute's Risk Information Management System (SGI-RISCOS-IG), 40 areas were identified, with 175 risk sectors (17\% at very high risk, $26 \%$ at high 

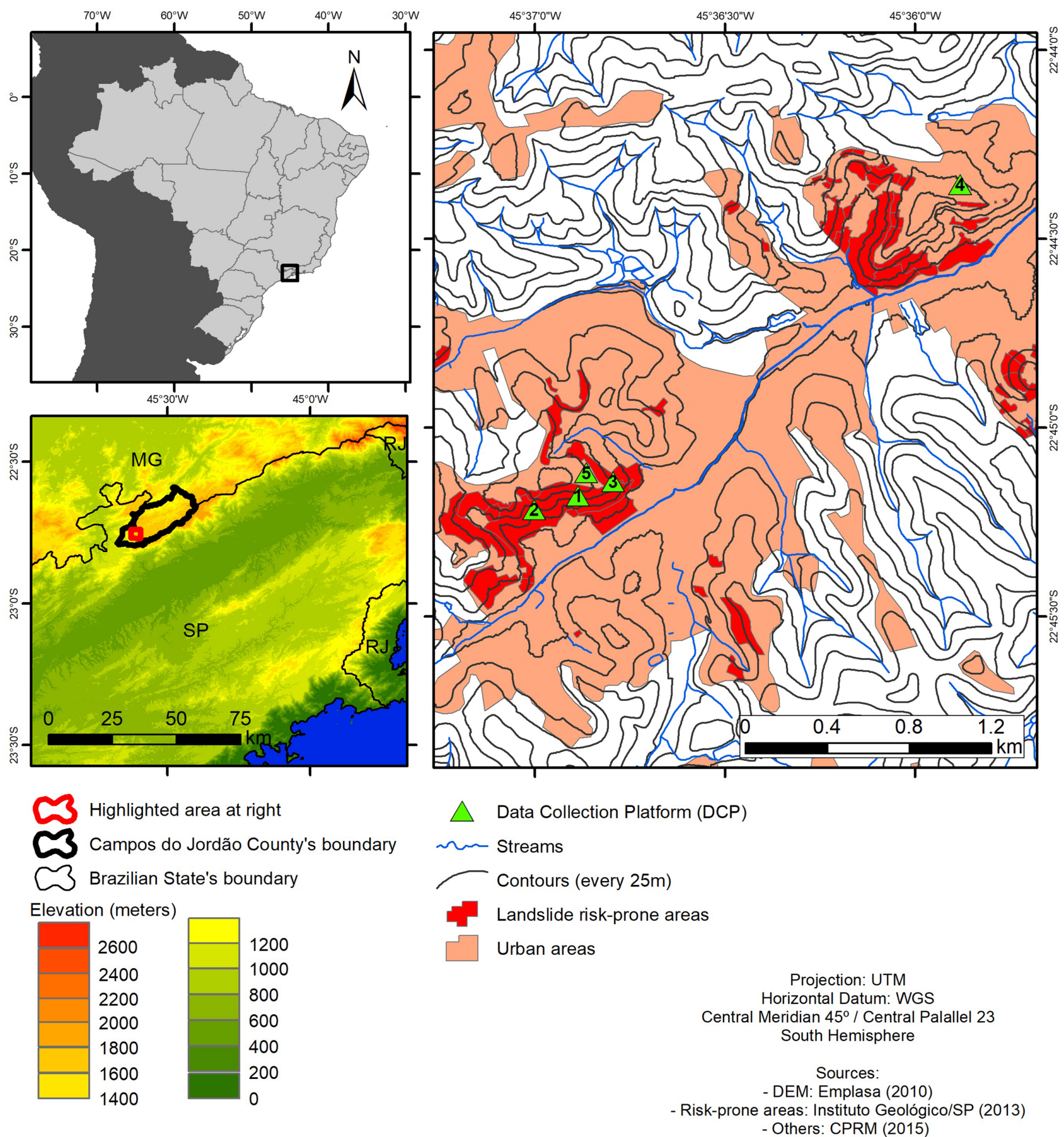

Figure 2. Localization Campos do Jordão and Data Collection Platform (DCP).

risk, $38 \%$ at medium risk and $19 \%$ at low risk). These risk areas were emerged from the occupation of forested zones with the construction of new neighborhoods [10].

In the year 2000, the IPT (Institute of Technological Research) carried out a survey that determined that 7000 people and 1500 houses were subject to hazards. The areas identified were Morro do Britador, Vila Albertina, Santo Antonio, Vila Nadir and Vila Paulista Popular [11]. 
Given the vulnerable conditions of the city, a database was compiled with the record of the landslides occurrences. From 1999 to 2013, were identified 51 recorded on landslides, in 43 districts of the municipality [12].

\section{Development of the SOLAM Integrated Analysis Software}

Solam was written in PYTHON 3 language, using the Spyder IDE (Integrated Development Environment). The created algorithm allows the visualization of the collected data by the DCP, as presented in Figure 3.

The first step of the algorithm is transferring the files containing the sensor data records. The graph generated from Solam reflects the user's initial input, so the result represents the parameters for a pre-established period time.

These files are sent by each DCP to a computer that stores the information. The data acquisition occurs every 10 minutes. To perform a more detailed analysis of the time of infiltration and flow of the water in the soil during the precipitation.

The user must enter the initial input for the software to select the data to be presented in the results. Therefore, the DCP and the profile must be chosen, each DCP currently has between 2 and 3 profiles installed with soil moisture sensors, so the user must select the profile of interest. The precipitation index (hourly intensity or cumulative rainfall) must then be selected, as well as the period to be analyzed.

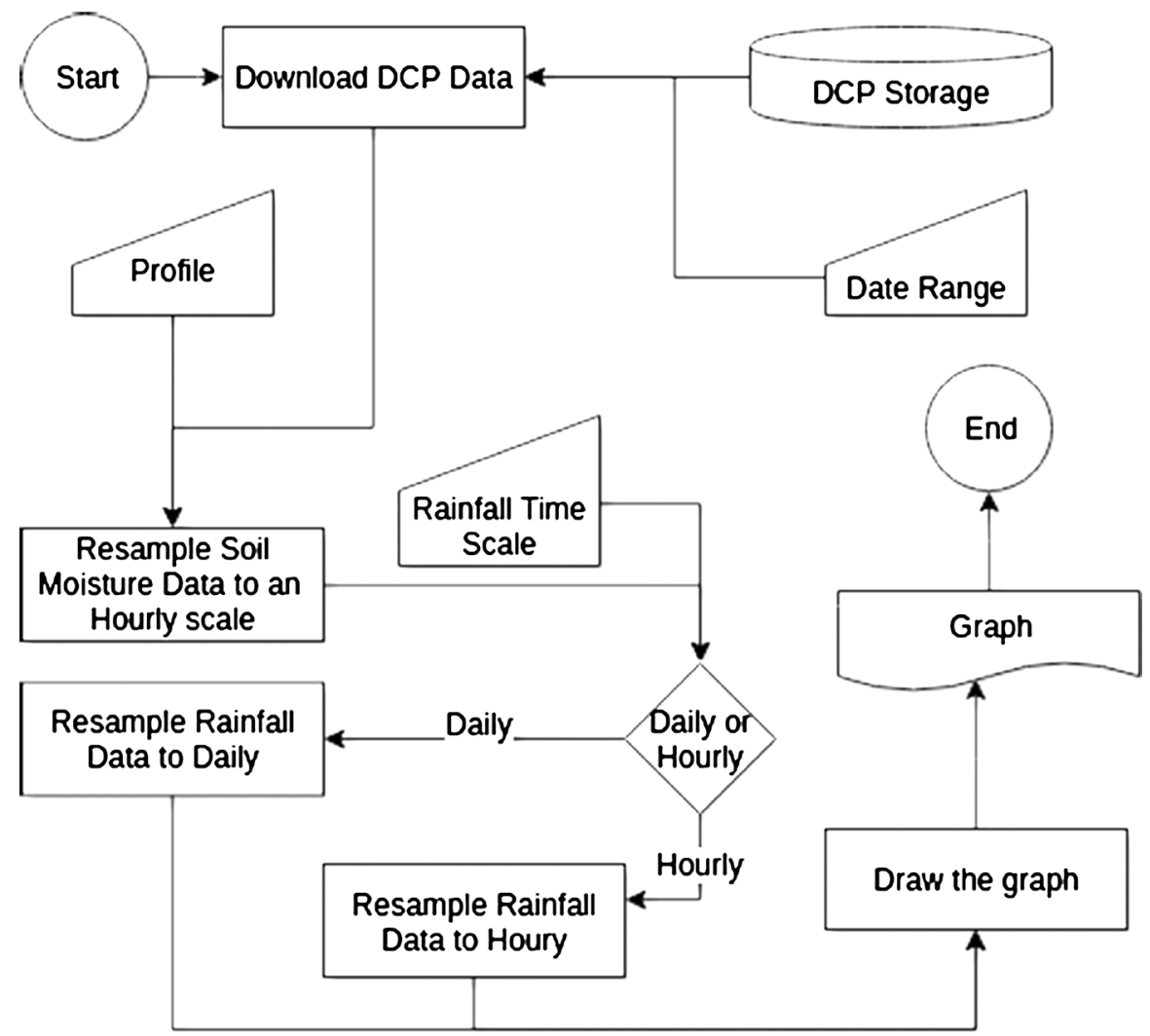

Figure 3. Schematic plot with the sequence of the algorithm Solam. 
In Figure 4 is presented the result of the algorithm. The upper portion pf the graph presents the DCP code, period and chose precipitation indexes. The graph has two vertical axes representing the volumetric soil moisture (right hand side) and the precipitation index (left hand side). The colored curves shown at the bottom of the graph correspond to the variation of soil moisture for the 6 sensors installed every $50 \mathrm{~cm}$ up to $3 \mathrm{~m}$ depth. The dashed blue line represents the cumulative rainfall and the vertical blue bars at the top of the graph correspond to the precipitation indexes chosen by the user.

\section{SOLAM Software Application to Define Environmental Thresholds}

Figure 4 shows an example of the graph generated by the software, from 2017-04-03 to 2017-10-03, in which several landslides occurred, for the purposes of to define critical thresholds of precipitation and soil moisture that can be used in the emission of alerts for the preventive evacuation of people from hazardous areas.

After three rainfalls events, there was a significant increase of soil moisture, followed by landslides events on March $6^{\text {th }}$ to $8^{\text {th }}, 2017$. In Figure 4 the increment in the soil moisture was highlighted by the black circles a, b, c and d. In general, it is possible to analyze some important aspects in the peak moments over the rainfall.

In the first rainy event (1), with almost $40 \mathrm{~mm} / 24 \mathrm{~h}$ of rain registered, only the shallow sensors, installed up to 1.5 meters deep, registered an increase in soil

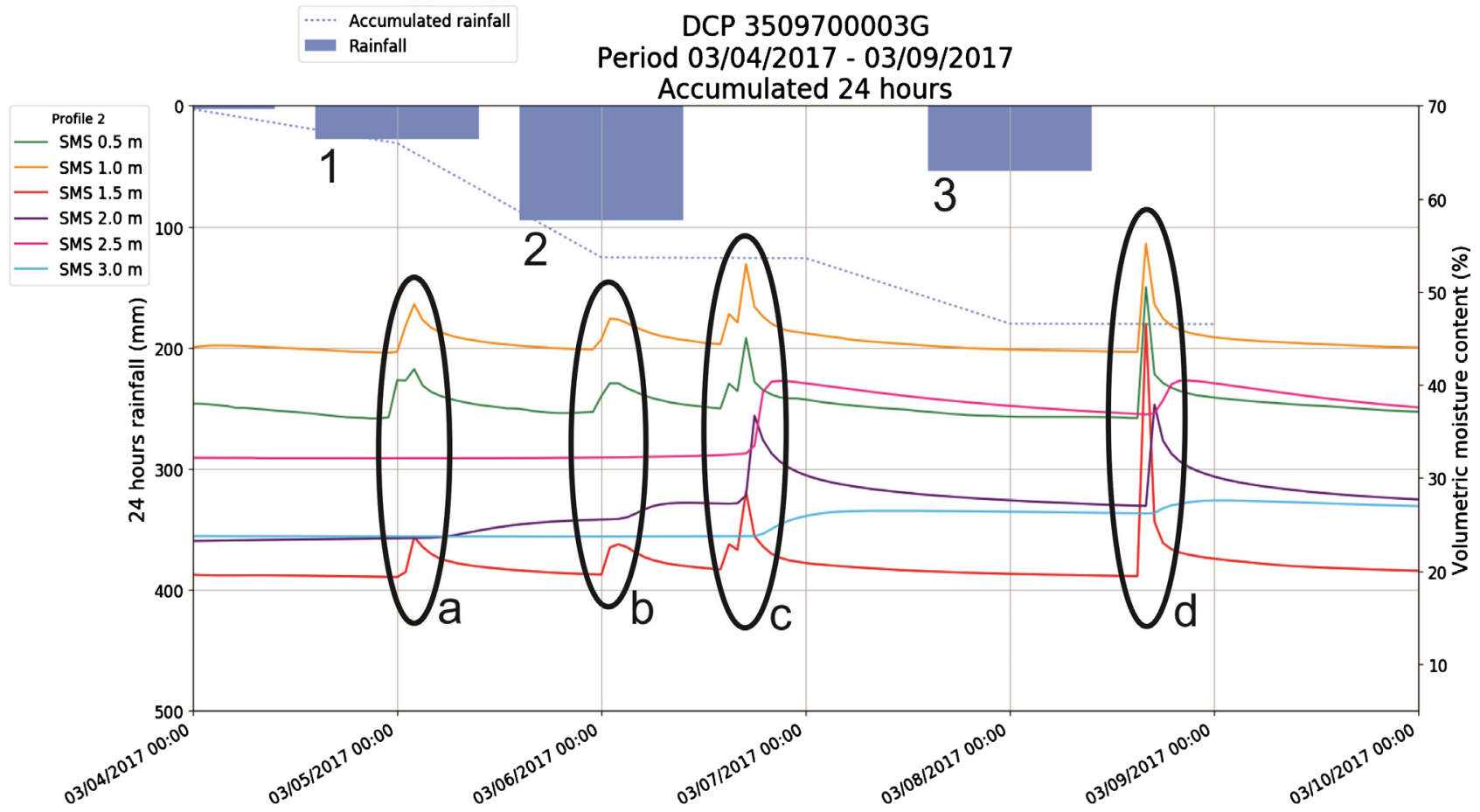

Figure 4. Graph generated by Solam Integrated Analysis Software-SMS: Soil Moisture Sensor (source: CEMADEN information platform). 
moisture. During this day there were no register of landslides (Circle a).

The second rainfall event (2) recorded $95 \mathrm{~mm} / 24 \mathrm{~h}$, which may have caused the increase of soil moisture in the sensor located at $2.0 \mathrm{~m}$. After this gain in soil moisture there were landslides at the end of day (2017-06-03).

During the March $6^{\text {th }}$ the rain caused an increase in soil moisture, presenting two peaks on the same day. So, these rainfall events do not allow the soil to drain the infiltrated water, increasing the possibility that the wetting front reaches the deeper layers.

For this kind of scenario (like 2017-06-03), adequate monitoring is needed to be able to issue an early warning of the possible events based on the critical thresholds defined according to soil behavior, considering the time of a possible evacuation.

The software represents an innovative tool to visualize the variation in soil moisture and enables defining the critical values that should not be reached during the rainy periods. These soil moisture percentages represent the environmental thresholds that are defined from the analysis of several landslide events with a similar behavior pattern.

As the data storage has been performed since 2014, allowing the study of the same landslides from all the installed DCP, evaluating if there is a general behavior of the region and comparing the speed wetting front and the capacity to drain the water over and after the rain. This analysis permits to define critical values for issuing alerts.

In the rainy event 3 , with $55 \mathrm{~mm} / 24 \mathrm{~h}$ all the sensors recorded a significant increase in soil moisture, showing that the wetting front in the soil profile reached critical depths (greater than 2.0 meters). This situation indicates a higher probability of slopes rupture. During these two increasing soil moisture situations (c and d), 11 landslides were registered by the Civil Defense.

Figure 5 shows the landslides that occurred on the days analyzed in this article. The yellow points represent the events that occurred on March $6^{\text {th }}$ and the red points on March 8th, while the blue triangles represent the installed DCP.

The sensor located at $1.5 \mathrm{~m}$ depth showed the greatest variation (red curve) for the time analyzed in Figure 4, especially for event d, increasing soil moisture by $135 \%$, starting with a value of $19 \%$ up to $46 \%$, with respect to soil moisture registered on 2017-04-03. This shows how infiltrated water over a short period of time increases soil moisture due to rain for consecutive days.

The blue curve $(3.0 \mathrm{~m}$ depth) presented the smallest variation for the time analyzed; it was observed an increase in soil moisture of $3 \%$, started at $24 \%$ for $03 / 04 / 2017$ and ended at $27 \%$ for $03 / 09 / 2017$. The infiltration process usually is slow, thereby at this depth, when the soil moisture raises the occurrence probability of landslide is higher.

The purple curve located at $2.0 \mathrm{~m}$ depth exhibited an increase in the soil moisture steady and slowly, after the rain of March 6th. This layer failed to drain the water from the first rain (1). 

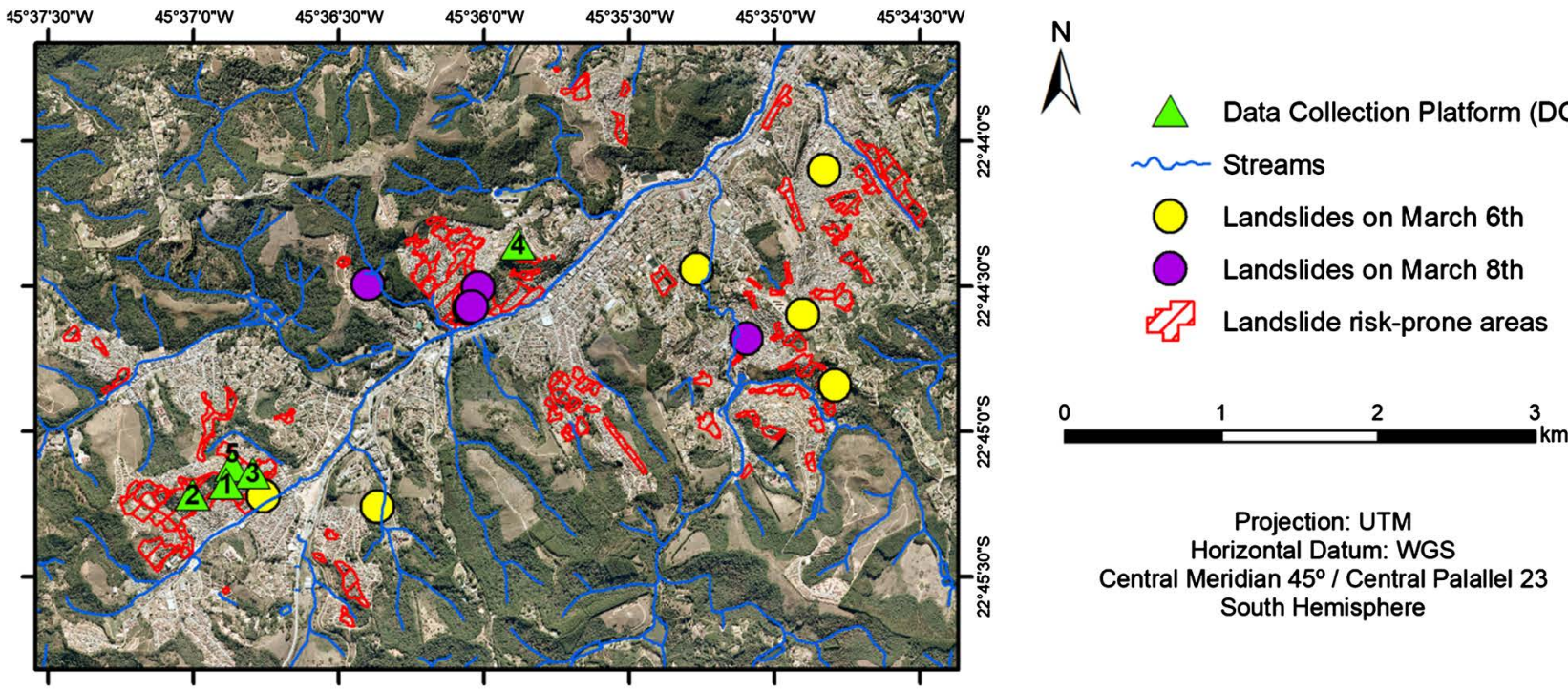

Projection: UTM Horizontal Datum: WGS Central Meridian $45^{\circ} /$ Central Palallel 23 South Hemisphere

Figure 5. Localization events landslides-The yellow points represent the events that occurred on March $6^{\text {th }}$ and the red points on March $8^{\text {th }}$. (source: SIDEC-Civil Defense Integrated Information System of Sao Paulo State).

The curve that corresponds to the sensor located at $2.5 \mathrm{~m}$ depth (pink curve) presented the increase in soil moisture only after the peak in the blue curve (2.0 $\mathrm{m})$. Therefore, the wetting front was able to raise the soil moisture to $2.5 \mathrm{~m}$ depth, only after crossing the previous layers soil.

The yellow and green curves ( 0.5 and $1.0 \mathrm{~m}$ respectively) had a similar behavior that increased the soil moisture by steady stages, after the rains on March $6^{\text {th }}$ and $8^{\text {th }}$, had the higher values.

According to the graph, when the wetting front begins to increase the soil moisture in the sensor located at a depth of $2.0 \mathrm{~m}$, attention should be paid to this variation to emit the alert at the right time, thus avoiding losses due to possible landslide. Thus, after the landslide records, monitoring should continue and predict new emergency events, generating alerts at the right time managing to notify the affected communities [7].

Another interesting observation about the soil layers located below $2.0 \mathrm{~m}$, they could not drain the water and return to the initial humidity percentage of 03/04/2017. Therefore, when 03/08/2017 there was another rain, more landslides occurred.

Further, the software helps to define the exact hour of the values of soil moisture peaks and rainfall occurrence. This hour scale date permits to obtain more detailed information about the events; which is very difficult in most landslides events.

Another feature of the software is the dashed line reflects the cumulative rainfall, allowing determining the total rainfall (in $\mathrm{mm}$ ) for a specific period.

With the option of several time periods for analysis, the software allows a better understanding of the water circulation behavior in the soil over time, evaluating the relevance of each rain event to the significant increase of moisture along the soil profile, until the critical thresholds for deflagration of the 
landslides are obtained

\section{Conclusions}

The software improves the analyses and interpretation of the geotechnical DCP, being able to identify rainfall variability patterns and soil moisture.

The presentation of the results in an automated, simple and clear way, permits to interpret the data collected and to define behavior patterns before, during and after the landslide events. Defining the maximum values of rainfall and soil moisture for landslides registered events allows establishing critical environmental thresholds, being the main objective reached with the developed software.

Consequently, it will be possible to define critical environmental thresholds, based on empirical relationship between historical analysis of rainfall and landslide occurrence. Finally, these critical values will be used in the warning system.

Currently, Cemaden does not have a geotechnical data platform that allows sending alerts with greater precision basing on the soil moisture. This software will permit a complete analysis of landslides in risk areas.

The final aim of the project is created tools to help in the process to send alerts in the right time in case of landslides and finally save lives; in this context this tool needs improvements and joins with other algorithms that calculate, for example, the infiltration of water and the factor of safety of slope elasticity in analysis.

\section{Acknowledgements}

The authors would like to thank Cemaden for enabling them to conduct research and provide the equipment needed for field monitoring as well as to write the algorithm in the office. Further, the authors would to thank the team of IT Cemaden especially to João Garcia by monitoring the algorithm development. Finally, the Civil Defense of Campos do Jordão for the support to carry out the activities in the city. CAB and LVAL thanks to Conselho Nacional de Desenvolvimento Científico e Tecnológico (CNPq) for the Research Fellowship Program (grant 300610/2017-3) - (300538/2017-0).

\section{Conflicts of Interest}

The authors declare no conflicts of interest regarding the publication of this paper.

\section{References}

[1] Baum, R.L. and Godt, J.W. (2010) Early Warning of Rainfall-Induced Shallow Landslides and Debris Flows in the USA. Landslides, 7, 259-272.

https://doi.org/10.1007/s10346-009-0177-0

[2] Chae, B.G. and Kim, M. (2012) Suggestion of a Method for Landslide Early Warn- 
ing Using the Change in the Volumetric Water Content Gradient Due to Rainfall Infiltration. Environmental Earth Sciences, 66, 1973-1986.

https://doi.org/10.1007/s12665-011-1423-Z

[3] Santoro, J., Andrade, E. and Brollo, M.J. (2015) Campos do Jordão (SP): Mapeamento de riscos de escorregamentos no morro do britador. $8^{\circ}$ Simpósio do Cretáceo de Brasil.

[4] Ab'sáber, A.N. (1996) O domínio morfoclimático dos mares de morros no Brasil. USP, Instituto de Geografia, São Paulo, 9 p. (Geomorfologia, 2).

[5] Rosa, A.F. and Cortez, A.T.C. (2010) A problemática socioambiental da ocupação urbana em áreas de risco de deslizamento da "Suíça Brasileira". Revista Brasileira de Geografia Física, 3, 33-40. https://doi.org/10.26848/rbgf.v3i1.232610

[6] CPRM (2011) Atlas Pluviométrico do Brasil. http://www.cprm.gov.br/publique/Hidrologia/Mapas-e-Publicacoes/Atlas-Pluviome trico-do-Brasil-1351.html

[7] Aleotti, P. (2004) A Warning System for Rainfall-Induced Shallow Failures. Engineering Geology, 73, 247-265. https://doi.org/10.1016/j.enggeo.2004.01.007

[8] Mendes, R.M., De Andrade, M.R.M., Tomasella, J., De Moraes, M.A.E. and Scofield, G.B. (2018) Understanding Shallow Landslides in Campos do Jordão Municipality-Brazil: Disentangling the Anthropic Effects from Natural Causes in the Disaster of 2000. Natural Hazards and Earth System Sciences, 18, 15-30. https://doi.org/10.5194/nhess-18-15-2018

[9] Modenesi-Gauttieri, M.C. and Hiruma, S.T.A. (2004) Expansão urbana no planalto de Campos do Jordão: Diagnóstico geomorfológico para fins de planejamento. $R e-$ vista do Instituto Geológico, São Paulo, 25, 1-28. https://doi.org/10.5935/0100-929X.20040001

[10] Mendes, R.M., De Andrade, M.R.M., Graminha, C.A., Prieto, C.C., De Ávila, F.F. and Camarinha, P.I.M. (2017) Stability Analysis on Urban Slopes: Case Study of an Anthropogenic-Induced Landslide in São José dos Campos, Brazil. Geotechnical and Geological Engineering, 36, 599-610.

https://doi.org/10.1007/s10706-017-0303-Z

[11] Ahrendt, A. (2005) Movimentos de massa gravitacionais-Proposta de um sistema de previsão: Aplicação na área urbana de Campos do Jordão-SP. Tese de Doutorado, Escola de Engenharia de São Carlos, Universidade de São Paulo (EESC/USP), São Paulo, 364 p.

[12] CEDEC (2013) Termos de cooperação técnica firmados com a coordenadoria estadual de defesa civil, \#1. 